\title{
CIDADES NO ESPAÇO DAS REDES: novas centralidades e periferias urbanas na sociedade informacional ${ }^{1}$
}

\author{
SUSANA FINQUELIEVICH \\ Instituto de Pesquisa Gino Germani \\ Faculdade de Ciências Sociais da Universidade de Buenos Aires,
}

\section{As cidades: Anciãs ou divas?}

O que implicam atualmente os conceitos tão utilizados pelos urbanistas, de cidades centrais e periféricas, na transição da Sociedade Industrial para a Sociedade da Informação, de acordo com alguns, ou do Conhecimento, de acordo com outros? O que significa a centralidade em um mundo globalizado e em uma sociedade de redes? As cidades centrais e periféricas, coincidem necessariamente com as metrópoles dos países respectivamente centrais e periféricos?.

Este trabalho tem sua origem em uma conversação informal no Rio de Janeiro, com a economista e urbanista espanhola Maitê Martínez Pardo². Perguntávamo-nos se os conceitos de cidades centrais e periféricas que se aplicavam na Sociedade Industrial, poderiam continuar a ser usados na chamada Sociedade Informacional. As questões potencializavam-se mutuamente: Estas centralidades e periferias são físicas, ou seguem outra geografia de tipo virtual? E qual é o centro, o marco zero que serviria de referência? Há um único centro, ou múltiplas centralidades? Este artigo não pretende responder a estas perguntas, mas suscitar o debate ao redor de uma questão necessária na atual reflexão dos investigadores urbanos.

As cidades ainda são importantes? indagava-se Saskia Sassen (1996). Muitos peritos urbanos e decisores do planejamento urbano e regional asseveraram que a globalização e as novas tecnologias de informação e comunicação (TIC) assinalavam o fim da importância econômica das cidades. Esta não é uma fantasia: de fato, muitas cidades têm sofrido em diferentes graus a repercussão da economia globalizada. Inúmeros centros urbanos que brilharam no passado por seu poder industrial, enfrentam atualmente graus diversos de decadência, tanto no mundo mais desenvolvido como nos países considerados periféricos. Mesmo nos Estados Unidos, basta circular por cidades outrora economicamente poderosas, como Búfalo, para perceber esta realidade. Em uma era marcada pelo "offshoring" de fábricas, o incremento da fragmentação urbana, a expansão das redes mundiais de empresas, e as operações imobiliárias que deslocalizam populações dos centros urbanos para os subúrbios, os observadores urbanos teriam razões válidas para supor que as cidades se tomariam obsoletas no curto prazo. Sassen (1996) observa que, desafiando estas predições, algumas cidades concentraram em seus territórios um importante poder econômico e político.

No ensaio "Whose City Is It? Globalization and the Formation of New Claims", em "Cities

1 Uma versão prévia deste artigo será publicada como capítulo do livro coordenado por Ana ClaraTorres Ribeiro: "A face nova da América Latina: Cidades, planejamento e ação", Rio de Janeiro-Buenos Aires: CLACSO.

2 A Maitê Brown Martínez devemos muitas das idéias e reflexões desenvolvidas neste artigo, que é um primeiro passo para trabalhos futuros. 
and Citizenship" (1996), Saskia Sassen argumenta que a cidade é o locus das novas reivindicações postuladas por diferentes classes e setores econômicos. Os representantes dos interesses do capital global baseiam suas propagandas na importância de uma infraestrutura urbana de último tipo, high-tech, para poder desenvolver suas capacidades para organizar de forma eficiente seus investimentos no exterior e para atrair investimentos estrangeiros. Os representantes dos grupos de trabalhadores sub-remunerados resistem a estes apelos. Esta força de trabalho, constituída majoritariamente por mulheres, imigrantes e pessoas de cores e culturas freqüentemente alheias às dominantes, respondem através de mobilizações urbanas (ou baseadas em cidades, ou expandidas a partir delas) aos objetivos do capitalismo global. Esta tensão não só falaria do novo e forte ressurgimento de uma vida (politica, social, econômica, cultural) urbana, mas muito também põe em questão que cidades são "centrais" e quais são periféricas, nos primeiros anos do Terceiro Milênio.

A cidade e as redes telemáticos: Fim da cidade ou novo protagonismo? Esta é a interrogação primordial que deu origem a iniciativa de uma investigação conjunta ${ }^{3}$ entre uma equipe brasileira e uma argentina ${ }^{4}$ da qual este artigo é um dos primeiros produtos. Um dos objetos fundamentais de nossa reflexão é a "mutação" das cidades e metrópoles no mundo contemporâneo, e particularmente na América Latina, relacionada - enquanto condição e resultado - ao avanço de novas formas de comunicação baseadas no meio técnico-científico - informacional das redes mundiais de computadores. Decidimos abordar o trabalho a partir da reflexão sobre as novas centralidades e periferias urbanas na sociedade das redes.

De acordo com a teoria de Sassen $(1991,1994,1996)$, três fatores da economia atual explicam por que uma rede de trinta a quarenta "cidades globais" tem mais importância do que nunca. Em primeiro lugar, a economia global não é simplesmente um mercado, mas um sistema que necessita do trabalho de administração especializado que está concentrado nas cidades. Em segundo lugar, as privatizações e as desregulações transferiram certas funções dos governos nacionais, regionais e locais para o setor privado, o que faz com que estas atividades se centralizem. E, por último, a digitalização significa que os setores econômicos dominantes necessitam de acesso a uma infraestrutura de serviços que se encontra precisamente nos centros financeiros das cidades. Em vez de tornarem-se obsoletas, estas cidades concentram funções de controle, servem como lugares de produção para as atividades financeiras e para as indústrias líderes do chamado período "pós-industrial", e proporcionam mercados nos quais as empresas e os governos podem adquirir os instrumentos financeiros e tecnológicos, assim como os recursos humanos que necessitam.

Há atualmente um intenso debate acadêmico sobre estes processos urbanos, para o qual desejamos contribuir com este trabalho. Discute-se sobre o papel das cidades como focos de produção de indústrias de TIC, de inovações tecnológicas, econômicas e sociais, incluindo os movimentos antiglobalização. Uma rede mundial de cidades como lugares estratégicos da economia global (não apenas Nova Iorque, Londres, Tóquio, Paris, Frankfurt, Zurique, Amsterdã, Los Angeles, Sidney, e Hong Kong, mas também São Paulo, Buenos Aires, Bangcoc, Taipei, e Cidade do México) engendra uma nova geografia econômica mundial que atravessa as fronteiras nacionais e a tradicional divisão Norte-Sul da economia industrial. É inevitável, pode-se supor, a emergência de uma geografia política paralela.

As cidades, lembram Castells (1996 e 2000) e Sassen (1996), sempre estiveram profundamente incrustadas nas economias regionais, muitas ainda permanecem, mas as cidades globais tendem a desconectar-se de seus países. Isto colide com um princípio fundamental das teorias econômicas tradicionais: que os sistemas urbanos promovem a integração regional e

3 A cidade e as redes telemáticas: Fim da cidade ou novo protagonismo?, Projeto de cooperação binacional Brasil-Argentina, financiado pela CAPES, Brasil e Secretaria de Ciência y Tecnologia, Argentina, 2001-2003.

4 As equipes são respectivamente o Instituto de Pesquisa e Planejamento Urbano e Regional da Universidade Federal do Rio de Janeiro, coordenada por Rainer Randolph, e INFOPOLIS, Área de Estudos Urbanos, Instituto de Pesquisas Gino Germani, Faculdade de Ciências Sociais, Universidade de Buenos Aires, coordenada por Susana Finquelievich. 
nacional. Em síntese, as atuais conjunturas mundiais exigem uma renovação nas reflexões acadêmicas e na investigação urbana, fundamentalmente sobre as seguintes questões:

- TIC e globalização. A digitalização reorganizou o espaço econômico e social. Emerge uma nova geografia de atividades econômicas, sociais, políticas que flutua entre o território presente e o ciberespaço, ou coexiste simultaneamente em ambos. Portanto, necessitamos de mais e melhores investigações sobre os impactos das TICs sobre as redes econômicas e sociais urbanas, assim como sobre sua expressão espacial.

- A distribuição da infra-estrutura eletrônica e de telecomunicações, e as condições para seu acesso podem acentuar ou morigerar desequilíbrios econômicos urbanos e regionais. Torna-se premente entender quais estratégias podem assumir as cidades em relação à trama destas redes e para a conectividade da maioria da população.

- Surgem novos conceitos, como o das cidades enquanto meios inovadores e sua relação com as regiões circunvizinhas e seus países de origem. Até mesmo se esta nova geografia estivesse determinada por cidades centrais e periféricas, mais do que por países desenvolvidos e subdesenvolvido, na atualidade ainda não há paridade - como para a redistribuição dos salários, expansão equilibrada de infra-estruturas e serviços, papel do Estado, participação cidadã - entre as cidades desenvolvidas nos países desenvolvidos, e as cidades em desenvolvimento nos países periféricos.

\section{As cidades como pontas de lança da inovação}

Neste trabalho, fortemente baseado nos conceitos de Castells, Hall e Sassen, pretende-se avançar no debate e construir novos conceitos. A hipótese básica, a primeira com a qual trabalhamos, é que esta mudança caracteriza-se pela superação das cidades industriais, enquanto elemento estruturante dominante da organização em diferentes escalas (níveis); são identificados sinais do surgimento de uma sociedade baseada em formas inéditas de convivência social que deixa de ter sua base nas formas clássicas cotidianas (família, bairro e comunidade (local)), e que eventualmente abandonam seus enclaves territoriais para tecer redes sociais globais. Simultaneamente, constrói-se uma nova hierarquia urbana na rede mundial de cidades. Isto já foi estudado intensivamente por Saskia $\operatorname{Sassen}^{5}$ e pelo próprio Castells, criando a classificação de cidades globais e cidades nodais, de acordo com a importância dos fluxos financeiros e políticos que concentram.

Mas também (e esta é nossa hipótese fundamental) as cidades podem ser classificadas em centrais e periféricas no sistema urbano da transição para a sociedade informacional, de acordo com sua capacidade em se tornar meios de inovação. Por lugar (ou meio) inovador, Castells e

5 Para Sassen (1994), a mundialização da economia implica em novos custos e oportunidades para as grandes cidades e áreas metropolitanas. Antes, consideravam-se apenas dois atores: a economia mundial (ou o sistema internacional) e os governos nacionais. Agora, há um terceiro protagonista: as cidades mundiais. Sassen resume sua teoria em quatro elementos fundamentais: a) A mundialização da economia e o influxo crescente de tecnologias e indústrias da informação, assim como as finanças, levaram à concentração massiva de recursos nas cidades. As empresas que operam ao nível mundial necessitam da infraestrutura telemática avançada e de mercados de recursos humanos que geralmente só as grandes cidades ou metrópoles podem oferecer. b) A mundialização da economia incrementou a complexidade das operações econômicas: as empresas necessitam comprar insumos cada vez mais especializados. As grandes cidades são os lugares mais adequados para a produçao desses serviços especializados. As empresas que compram esses serviços já não necessitam ter suas sedes em grandes cidades, ainda que prefiram ter acesso à rede elaborada e concentrada de firmas de serviços situadas nas urbes. c) A privatização e a desregulação resultaram em um deslocamento de funções de governo e coordenação para o setor privado: freqüentemente, isto implica por sua vez em um repasse de funções e fundos do governo nacional ao governo local. O desafio consiste em transformar esta mudança econômica em um marco político que capte todo o poder que possa atribuir-se ao governo local. d) Em grande medida, a economia mundial está formada por uma rede transfronteiriça de pontos estratégicos, particularmente cidades mundiais. Sassen interroga como transformar esta rede em um espaço político também transfronteiriço (p. ex., mediante a formação de redes e a criação transfronteriça entre prefeitos de grandes cidades, redes cidadãs globais ou trasnacionais, etc.) 
Hall (1998) entendem "o sistema de estruturas sociais, institucionais, organizacionais, econômicas e territoriais que criam as condições para uma geração contínua de sinergias e seu investimento em um processo de produção que se origina a partir desta capacidade sinérgica, tanto para as unidades de produção que são parte deste meio inovador, como para o meio em seu conjunto". O desenvolvimento destes tipos de meios é, na passagem do milênio, não só um fator decisivo para o desenvolvimento econômico local, mas também uma questão de prestígio social e político. As cidades - meios de inovação seriam aquelas capazes de concentrar de forma interrelacionada elementos como:

- A produção local de bens e serviços de alto valor agregado em tecnologias da sociedade informacional. Isto se refere de fato ao hardware e software (como exemplificariam os casos de Seattle e o Vale do Silício nos Estados Unidos, Tsukuba no Japão, e Bangalore na Índia), mas não de forma única nem exclusiva: refere-se também à capacidade das cidades em atrair empresas inovadoras, no sentido, não de fabricar artigos eletrônicos, mas de usar TICs e principalmente a Internet como lugar e meio de organização em rede. $\mathrm{O}$ exemplo paradigmático seria Cisco Systems ${ }^{6}$.

- Consumo individual e sobretudo coletivo, de bens e serviços intensivos em TIC, quer dizer, o consumo de serviços urbanos que utilizem TIC para seu melhor funcionamento e administração: educação, saúde publica, transportes, segurança, etc.; redes técnicas urbanas, como água e saneamento, administradas por meio de TIC; e, fundamentalmente, o governo eletrônico destas cidades. Isto não se limita a abrir portais ou homepages - lugares web com os dados do Estado para informar aos cidadãos e facilitar os trâmites internos; significa neste caso colocar o governo local em rede, na Intemet, no sentido de contribuir para produzir uma transformação na cultura política e institucional, para que os cidadãos possam ter acesso às informações que lhes interessam, e participar ativamente nas decisões ligadas à sua qualidade de vida e a seus direitos como cidadãos.

- A emergência de novas formas de organização social que utilizem como suporte as TICs. Nós nos referimos especificamente às redes eletrônicas de cidadãos, definidas pela Associação Espanhola de Redes Cidadãs como sistemas de intervenção, instrumentalização, articulação e promoção do desenvolvimento local em todas as suas vertentes... Os distintos grupos e movimentos sociais têm nas redes um meio de comunicação e um foro para fazer chegar suas idéias e propostas aos cidadãos e uma ferramenta para interagir com grupos de interesses semelhantes em outras partes do mundo.

Estas cidades concentrariam as interações de capitais de risco, ações estatais tendendo a converter-se em cidades-chave da nova economia, e criação de conhecimento de alta qualidade em estabelecimentos universitários e centros de excelência de pesquisa e educação, além de novas formações sociais que usam TIC como suporte e espaço de organização de uma cidadania inovadora.

O papel das cidades na Era da Informação é ser meio produtor de inovação e de riqueza, capaz de integrar a tecnologia, a sociedade e a qualidade de vida em um sistema interativo que produza um círculo virtuoso de melhoria, não só da economia e da tecnologia, mas da sociedade e da cultura. As cidades que conseguissem isto, ocupariam um lugar central na nova sociedade.

6 Conforme Castells (1996), Cisco Systems, localizada no Vale do Silício, produz computadores e reuters - sistemas de direção dos fluxos da internet. E responsável pela venda de $80 \%$ destes equipamentos no mundo. Em sua homepage expõe ofertas tecnológicas de produtos e de soluções de engenharia. As empresas que desejem instalar seus sistemas de Intemet consultam a homepage e expressam suas necessidades. Cisco Systems tem uma fábrica própria e 29 fábricas privilegiadas, que não fazem parte da empresa. Estas fábricas consultam a home page e oferecem produtos adaptados às especificações técnicas de Cisco Systems. $85 \%$ das operações de Cisco Systems passam pela home page; $50 \%$ das vendas se realizam sem intervenção dos engenheiros desta empresa. A empresa paradigmática vende conhecimento tecnológico, mas também conhecimento de aplicações de engenharia e informação dos tipos de provedores existentes no mundo. 
Aquelas que não conseguisse desenvolver meios sociais, econômicos e tecnológicos inovadores, permaneceriam nas margens. De acordo com as capacidades e possibilidades das cidades para cumprir este papel, um novo mapa de centralidades e periferias urbanas, diferente do traçado na sociedade industrial, estabelecer-se-ia. Estes meios de inovação estariam territorialmente concentrados em cidades ou em suas áreas de influência, articulados e conectados através de redes de telecomunicações em escala mundial.

A terceira hipótese é que esta rede de cidades centrais e periféricas, definidas por sua capacidade de inovação, necessariamente não coincidirá com a hierarquia urbana atual de capitais, cidades médias e pequenas, em países e regiões desenvolvidas ou em desenvolvimento, nem com a hierarquia de Sassen de cidades globais e nodais. Como em uma sucessão de mapas transparentes sobrepostos, algumas cidades centrais, globais, ou as cidades hierarquicamente relevantes dos atuais norte e sul coincidirão com as cidade-nodais inovadoras, enquanto muitas outras não. Em síntese, e para retomar a interrogação principal propomos o enunciado de que só as cidades que se coloquem o objetivo de tornar-se meios inovadores - sociais, tecnológicos, econômicos, políticos - e que o alcancem, atingirão um novo protagonismo no espaço das redes, na Sociedade Informacional.

Surge daí uma inevitável reflexão: nem todas as cidades que criarem meios inovadores possuirão a mesma proporção de inovação em todas as áreas; algumas cidades serão notáveis por suas inovações tecnológicas; outras, por suas inovações sociais, culturais, ou econômicas. Em outras ainda, é possivel que uma fase inovadora seja antagônica a outra, até o ponto em que uma elimine ou debilite a outra. A evolução do trabalho, e a própria realidade complexa, confirmaram ou contradisseram estes conceitos iniciais.

Os objetivos do presente trabalho são fundamentalmente construir uma base conceitual de análise dos novos conceitos referentes às hierarquias urbanas específicas da sociedade da informação, assim como esboçar uma primeira tentativa de metodologia de pesquisa apropriada para a análise das novas centralidades e periferias urbanas, de acordo com as hipóteses antes enunciadas. $\mathrm{O}$ artigo não desenhará o novo mapa urbano da sociedade informacional, mas oferecerá aos "cartógrafos" sociais algumas ferramentas conceituais para explorar o novo território e explicitar a sua geografia.

\section{As diferentes percepções da cidade no espaço das redes}

Muito se discutiu sobre o porvir das cidades na transição de milênios. Para autores de ficção científica - particularmente para os contestatários do sistema - as cidades e seus habitantes estavam inexoravelmente destinados à catástrofe, em inúmeras e variadas formas. Mariano Fressoli $^{7}$ (2001) lembra que a ficção científica de esquerda assinala os perigos que o futuro encerra para os habitantes urbanos. Trata-se de uma extrapolação, de uma releitura dos afãs tecnológicos que dominam o presente, pontuando seu destino trágico e ignorando outras opções, em que a tecnologia poderia proporcionar mais soluções que destruições. Ballard (1962), em seu conhecido livro Billeniuin, mostra a cidade como um espaço fortemente limitado, no qual é quase impossível deslocar-se por causa do excesso de população. Em Concentration City, do mesmo autor, a urbe cresceu tanto que é impossível atribuir-lhe um centro ou uma periferia, um interior ou exterior: além de ter se tornado infinita, perdeu no processo sua história, seus limites e sua origem. A cidade que Gibson narra em Neuromancer é um espaço tenebroso complexo em sua diversidade de ambientes, intrincado em seu labirinto de subúrbios desindustrializados. Esta cidade é habitada pela violência e o mercado negro, como as cidades derrotadas nos pós-guerras

7 Mariano Fressoli, anotações da aula como docente convidado do "Seminario Introducción a la Sociedad Informacional" Carrera de Sociologia, Facultad de Ciencias Sociales, Universidad de Buenos Aires. Docentes: Susana Finquelievich e Silvia Lago Martinez, 2001. 
mundiais ou as atuais cidades países do Sul em bancarrota. "A lei e a ordem, seja por fastio, incapacidade ou estratégia, apenas a sobrevoam".

O surgimento (ou a construção) do ciberespaço está fortemente ligado, na percepção de alguns autores, à decadência da idéia tradicional da cidade. É possível pensar que os processos que descentralizaram e parcelaram a cidade são o ponto de partida para o aparecimento do ciberespaço. Fressoli (2001) sustenta que a complexidade das cidades atuais se visualiza em processos complementares. Um deles é o crescimento da mancha urbana, a extensão da cidade além de seus limites, a conjunção de áreas urbanas e suburbanas que se entrecruzam e confundem: a formação da megalópole rompe a antiga idéia da cidade como um espaço unificado e centrado, racionalmente orientada para um tipo de circulação definida. As atuais megalópoles cresceram e diversificaram tanto suas superfícies que é impossível imaginá-las como um todo, reconstruí-las como uma cidade.

A nova lógica espacial, definida por Castells (1996) como "espaço dos fluxos", modifica e reconstrói as funções da cidade. Fressoli (2001) agrega que as cidades narradas por Gibson (1995 e 1996) estão marcadas por estas características. Por um lado é impossível abarcar a complexidade de sua extensão, sua dimensão, uma extensão urbana que vai de Boston a Atlanta (como um antecedente distante da urbanização completa do planeta que vemos em Trantor (Asimov, 1978)); por outro lado, a mesma cidade é dividida em lugares diferenciados que impulsionam sua autonomia. A cidade de Chiba de Neuromancer é um espaço liberado para a experimentação do mercado negro em biotecnologias e armas. A Ponte, uma comunidade pseudoanarquista descrita por Gibson em Virtual Light, define-se pela solidariedade na reapropriação do espaço público, que lhes nega a própria cidade.

Do outro lado encontram-se os espaços exclusivos que tentam isolar-se da cidade, os hotéis internacionais, os bairros fechados que através da soma de desenho e segurança estabelecem ilhas independentes da cidade. Estes espaços são o prolongamento físico do espaço dos fluxos, o sítio criado para a interação segura das "elites gestoras dominantes." Um fio reúne as tendências de descentralização e multi-centralidade da cidade com o redesenho dos espaços exclusivos e isolados: a destruição do espaço público e a militarização da cidade. E todas estas visões catastróficas, mas não descabidas (no fundo limitam-se a extrapolar para o futuro as tendências dominantes atuais), são contemporâneas ao surgimento do ciberespaço como uma nova trama de relações sociais.

Rainer Randolph ${ }^{8}$ (2000) aponta para outro tipo (menos catastrófico) de desaparecimento da cidade. Percebe as cidades, não como atores, não como nós de redes regionais, nacionais ou globais, mas como cidades-redes em si mesmas. Transformações e representações urbanas refletiriam uma nova qualidade de circulação de bens e mercadorias, serviços (informações) e pessoas, tanto $n a$ cidade, como entre as cidades, onde o movimento toma-se cada vez mais "virtual" (informacional ou imaterial) e os equipamentos urbanos telemáticos necessários, pouco alteram o ambiente construído. Por conseguinte, as transformações não só se limitam à escala intraurbana (da estruturação e segregação da cidade), mas se expressam também em novas entrecidades (sistema urbano, rede de cidades) e em novos formatos de cooperação 1 competição interurbana.

Randolph (2000) demonstra como a grande cidade, em suas escalas inter e intraurbanas, perde atualmente seus atributos tradicionais de especificidade localizada - tornando-se questionável sua identificação como "ator" - em prol de novas relações nas quais a distinção entre as duas escalas toma-se cada vez mais enganadora: ao contrário de integrar-se em uma rede (hierarquia, sistema) onde ocupem "seu lugar", as metrópoles contemporâneas assumem cada vez mais o caráter de rede; encaminham-se, de forma crescente, para a essência da cidade-rede. Deste modo,

8 Para este ponto utilizamos (em grandes parágrafos, literalmente), o capitulo de Rainer Randolph (2000) "Las mutaciones de lo urbano: de la red de ciudades a la ciudad-red”, pp 21 a 38, in Finquelievich, S. (coord): Ciudadanos, a la Red, Buenos Aires: La Crujía, 2000 
a passagem para uma nova cidade", ou cidade-rede, deveria ser vista como um jogo articulado entre o avanço e o fortalecimento de uma virtualidade "urbana" (circuitos de comunicação mediados por computadores) e o conseqüente enfraquecimento e esvaziamento da "materialidade" da realidade urbana contemporânea (relacionada ao transporte de bens, mercadorias e pessoas, etc.). Este processo duplo e simultâneo está ligado às duas fases da circulação e movimento nos respectivos "meios urbanos", das tecnologias de circulação informacional e de circulação físico-material.

Para Manuel Castells (2000), a cidade da transição para a sociedade informacional define-se como a cidade da nova economia, a partir da transformação tecnológica e organizacional, e analisa qual é o papel das cidades nesta nova economia e na relação, problemática, que se estabelece entre esta nova economia e os processos sociais e institucionais urbanos. Fundamentalmente caracteriza a economia do conhecimento por três grandes traços interrelacionados:

- Está centrada no conhecimento e na informação como bases de produção da produtividade e competitividade, tanto para empresas como para regiões, cidades e países.

- É global, o que implica que as atividades econômicas dominantes - articuladas globalmente e funcionando como uma unidade em tempo real - funcionam em torno de dois sistemas de globalização econômica: a globalização dos mercados financeiros interconectados por meios eletrônicos e a organização a nível planetário da produção de bens e serviços e de sua gestão.

- Funciona em redes: redes descentralizadas dentro da empresa, redes entre empresas, e redes entre as empresas e suas redes de pequenas e médias empresas subsidiárias.

Esta economia em rede que permite uma flexibilidade extraordinária e adaptabilidade, é informacional, global e organizada em rede; nenhum desses fatores pode trabalhar sem o outro. Possui uma base tecnológica: tecnologias de informação e comunicação (TIC), de base micro eletrônica, com uma forma central de organização, a Internet. Castells sublinha o fato que a Internet não é uma tecnologia, mas uma forma de organização da atividade. "O que era a fábrica na grande organização na era industrial, é a Internet na Era da Informação" (Castells, 2000). As cidades desempenham um papel estelar, um duplo papel. Desenvolve a hipótese de que as cidades são fundamentais, tanto como produtoras dos processos de geração de riqueza no novo tipo de economia, como produtores da capacidade social de corrigir os efeitos desintegradores e destrutivos de uma economia de redes sem nenhuma referência a valores sociais mais amplos, mais coletivos ou não mensuráveis no mercado (como a conservação da natureza ou a identidade cultural).

As cidades são, empiricamente, os meios mais importantes de inovação tecnológica e empresarial. Castells e Hall (1994) confirmam que os meios de inovação tecnológica, quase sem exceção, são grandes áreas metropolitanas impulsionadas por cidades potentes: Paris, Marselha, Barcelona, Londres, Taipé, San José, etc. Estes meios de inovação metropolitanos são essenciais porque, através da sinergia que geram, das redes de empresas, de inovações, de capital, atraem continuamente os dois elementos-chave do sistema de inovação: a capacidade de inovaçao, quer dizer, talento, pessoas com conhecimento e idéias, e capital, sobretudo capital de risco, que é o que permite a inovação.

Como explica Sassen, a economia global possui nós, concentração territorial. Os meios de inovação estão territorialmente concentrados em cidades ou em suas áreas de influência, e articulam-se através de redes de telecomunicações em escala mundial. Um meio de inovação é um centro de atração. Castells (2000) demonstra empiricamente que são os meios de inovação 
territorialmente concentrados ao redor de cidades dinâmicas, que constituem as fontes de riqueza na nova economia. Para isto, é fundamental a relação entre cidade e universidade. As universidades são um motor de crescimento econômico, tecnológico e empresarial, mas também são um fator de criação de cidade. Atualmente, lembra Castells (2000), a universidade é um elemento essencial da dinamização do tecido urbano, dada a produção de força de trabalho qualificada, de inovadores e pessoas com idéias novas. O que conta é a capacidade de ação tecnológica em aplicações, em sistemas de software avançado e em tecnologias de redes de todo o tipo: tecnologias de telecomunicações. Este tipo de ação não se resolve com parques tecnológicos onde se podem concentrar grandes instalações industriais, são meios de inovação mais intensivos em inteligência do que em edificações. A problemática consiste em procurar as formas de articulação entre o território e estes mecanismos de inovação sociais, espaciais, econômicos, culturais, muito mais sutis, ligados à dinâmica própria da inovação e, em particular, da inovação de pequenas e médias empresas.

Castells (2000) estabelece um estreito vínculo entre políticas cidadãs e o desenvolvimento da nova economia e das novas tecnologias de informação: desenvolve a idéia de mercados locais de tecnologia baseados em políticas cidadãs e ambientais, intensivas em informação e em tratamentos avançados de informação, que compreenderiam desde a modernização dos serviços públicos até a criação de sistemas de participação-cidadã que articulem as formas de participação tradicionais e presenciais com formas de participação-cidadã através da Internet. Isto não só otimiza a gestão local, mas também cria mercados locais, mercados de partida potenciais para pequenas e médias empresas inovadoras locais, base do desenvolvimento futuro.

O sociólogo espanhol sublinha que a utilização, a apropriação da Internet por seus usuários em muitos níveis, gera novos tipos de tecnologia, e não só de usos dessa tecnologia. A utilização intensiva, em uma cidade com políticas inovadoras em termos de serviços públicos, de participação cidadã, de difusão da educação, de preservação do ambiente natural e construído, conduziria a um desenvolvimento de novas aplicações e, portanto, de novos usos e de novas tecnologias de comunicação que ampliam a gama de utilização da Internet. $O$ espectro se ampliaria dos usos comerciais, nos quais está baseado atualmente o desenvolvimento da Internet, para usos e aplicações de um espectro muito mais amplo que, além de gerar mercados importantes, também permitirão uma utilização da revolução tecnológica em termos de uma melhor qualidade de vida e de formas inovadoras de organização social. Neste processo, entusiasma-se Castells (2000), muda o lugar que esta cidade ocupa na hierarquia global.

\section{Cidade-bem, cidade-rede, cidade-ator}

Estas três visões urbanas, apesar de suas diferenças óbvias, possuem fortes pontos em comum: um deles é a concepção da cidade como bem estratégico, seja para ser renovada (Castells, 1996), despedaçada (Gibson, Ballard), ou re-questionada como cenário principal da exclusão / integração social nas sociedades contemporâneas (Randolph, 2000). Outro ponto comum é o conceito de que a "cidade" vive, hoje, uma nova conjuntura: sua revalorização como motor econômico, centro de inovação e difusão tecnológica e cultural, e lugar de encontro / associação / cooperação entre o Estado e a sociedade civil, entre o público e o privado. Um terceiro ponto um dos mais relevantes - é a concepção urbana como espaço das redes: redes técnicas, redes financeiras, mas principalmente, redes sociais, de potentes efeitos transformadores (com potencialidades de resistência ou de contestação, no caso dos autores de ficção científica, ou construtivas no sentido de uma reconstrução social, como concebem Castells (2000) e Randolph (2000)).

Em todo caso, colocam-se para as cidades do começo do terceiro milênio, novas questões: 
- A ruptura da relação salarial estável que conformou o sistema conhecido no Século de XX, e que força novas estratégias de sobrevivência individual e social.

- A transformação de conceitos tais como "urbano" (estendido tanto para modos de vida, crescimento de espaços periurbanos construídos, etc, antes considerados como "rurais"), ou "local" que já não se circunscrevem às fronteiras municipais.

- A modificação do binômio integração-exclusão, já que integrados e excluídos o são agora, além de seu pertencimento - localização no sistema sócio-econômico, por seu pertencimento ou localização entre os ricos e os pobres em informação, por sua integração ou não à sociedade informacional.

- E a - relativa - determinação do conceito de propriedade dos meios de produção' que até certo ponto se desvanece com as TIC, já que, ao contrário do que aconteceu com a propriedade dos insumos e ferramentas de produção da sociedade industrial, em uma sociedade em que o principal insumo é a informação, o conhecimento, já não é necessário ser o proprietário dos bens de produção para apropriar-se do insumo, que é ao mesmo tempo produto: qualquer um pode ter acesso ao conhecimento que circula pela Internet, recriá-lo, reformulá-lo, e redifundilo. Para isso, nem sequer é necessário possuir um computador: basta utilizar qualquer um dos lugares públicos de acesso, pagos ou gratuitos existentes, em número crescente nas cidades. De fato, isto não se refere ao conhecimento (privado, pago) utilizável para a produção privada de bens e serviços, nem tampouco ao transmitido na educação formal universitária, também paga na maioria dos países, principalmente ao nível de pós-graduação.

Estas questões sublinham a importância do desenvolvimento de meios inovadores nas cidades, assim como o surgimento e crescimento de diferentes tipos de redes, como redes entre empresas, entre empresas e universidades, entre cidadãos, governos locais, etc.

\section{Novas geografias e distâncias virtuais}

A European Telework Online, ou ETO, (www.Telework/netdist.htm) realizou um trabalho extremamente interessante sobre as distâncias que separam países diferentes da economia de redes. Seus conceitos baseiam-se na economia global de redes, ou Sociedade Informacional, a geografia do comércio e o desenvolvimento econômico está mudando rápida e profundamente. $\mathrm{O}$ quadro que a ETO (2000) construiu, e que incluímos aqui, mostra uma nova medição da "distância" baseada no custo relativo dos telefonemas internacionais. Quanto mais baixo o custo, menor é a nova distância. O custo relativo e, por conseguinte, a "nova distância" no trabalho da ETO refere-se ao custo das chamadas dos usuários entre o Reino Unido e os Estados Unidos (atualmente, a rota internacional mais competitiva), o que representa uma unidade de distância.

As estratégias nacionais entre a Inglaterra e os Estados Unidos tornaram os vínculos de comunicação entre estas duas economias o mais barato do mundo. As outras distâncias são mostradas como múltiplos desta unidade original. Por exemplo, a Áustria está duas vezes mais distante do "centro" da economia em rede que os Estados Unidos ou Inglaterra; Chipre, cinco vezes mais distante, a Bolívia dez vezes, as Seichelles quinze vezes. No caso do Brasil, a distância ao centro é de quase seis vezes $(5,9)$ a distância que separa os Estados Unidos do Reino Unido. A Argentina está ainda mais distante: 7,3 - abaixo de países como Papua Nova Guiné, Colômbia ou Venezuela. Este quadro mostra claramente os impactos das desregulações ativas e positivas nas telecomunicações. Nos países europeus, por exemplo, um telefonema da Grã Bretanha para a França, seu vizinho mais próximo, custa o dobro de uma chamada para o outro lado do Atlântico. Até mesmo a Austrália, quase nos antípodas, está mais próxima da França em termos de telecomunicações.

Estas distâncias e proximidades não deixam de ter impactos importantes nos países periféricos 
ou em vias de desenvolvimento, e particularmente sobre suas cidades. Algumas regiões da Índia (como Bangalore) tornaram-se atraentes para fábricas de desenvolvimento de software, mas uma empresa hindu que concorra com, por exemplo, empresas britânicas enfrenta custos telefônicos seis vezes maiores do que os custos da França, e quatro vezes maiores do que os custos de Israel, outro país que está desenvolvendo uma alta competitividade internacional na fabricação de software. Buenos Aires, que pretende implementar um pólo tecnológico no sul da cidade, deverá pagar custos telefônicos quatro vezes mais caros do que Paris, enquanto o Uruguai que entrou incipientemente no mercado internacional de software, teria custos telefônicos cinco vezes mais caros que os da França, o que implica em sérias desvantagens adicionais para Montevidéu como meio inovador em relação a Paris. Para o Brasil, por outro lado, os custos seriam um pouco menos do que três vezes na França.

Os custos usados por $\mathrm{ETO}^{9}$ para o trabalho comparativo são os custos de chamadas com desconto (chamadas com tarifas reduzidas) atualmente acessíveis nas companhias internacionais. Ao desenvolver o quadro de distâncias, o ETO comparou estes custos com as tarifas locais mencionadas pelos serviços com desconto em países que possuem um sistema de telecomunicações e uma economia liberalizada; as tarifas do quadro são em geral as menores a que se teve acesso. Em geral, a maioria dos consumidores paga mais que os custos sugeridos no trabalho do ETO, e é muito provável que a distância prática entre países classificados com distâncias de 2,0 ou mais no quadro sejam muito maiores que as cifras esboçadas. De acordo com o ETO, em países que possuem regimes de telecomunicações mais restritos (menos liberalizados) os consumidores estão em geral menos alertas ou menos informados sobre a acessibilidade de tarifas com descontos. Além disso, quanto mais liberal e competitivo for o regime de telecomunicações locais, menores serão os preços para as ligações comuns e maior e mais visível a concorrência entre as empresas que efetuam esses descontos.

\section{Distâncias telefônicas com base nos Estados Unidos e Reino Unido}

$\begin{array}{lrlr}\text { Estados Unidos } & 1.0 & \text { Libéria } & 8.6 \\ \text { Letônia } & 5.4 & \text { Gabão } & 12.4 \\ \text { Em. Árabes Unidos } & 8.1 & \text { Países Baixos } & 1.6 \\ \text { Burquina Faso } & 11.5 & \text { Lituânia } & 5.6 \\ \text { Reino Unido } & 1.0 & \text { Namíbia } & 8.6 \\ \text { Albânia } & 5.5 & \text { Índia } & 12.4 \\ \text { China } & 8.2 & \text { Bélgica } & 1.8 \\ \text { Zâmbia } & 11.5 & \text { Equador } & \mathbf{5 . 8} \\ \text { Suécia } & 1.3 & \text { Trinidad \& Tobago } & 8.6 \\ \text { Ilhas Virgens brit. } & 5.5 & \text { Coréia do Norte } \\ \text { Dominica } & \mathbf{8 . 3} & \text { França } & 12.4 \\ \text { Maurício } & 11.9 & \text { Filipinas } & 1.8 \\ \text { Canadá } & 1.4 & \text { Uganda } & 5.8 \\ \text { Ilhas Caiman } & 5.5 & \text { Kuwait } & 8.6 \\ \text { St. Lúcia } & 8.5 & \text { Alemanha } & 12.4 \\ \text { Qatar } & 11.9 & \text { Brasil } & 1.8 \\ & & & \mathbf{5 . 9}\end{array}$

9 O desenvolvimento do Telework On-line europeu esteve favorecido pelo ETD, uma iniciativa da Comissão européia (DGXIII) AGE programme, http://www.eto.org.uk/eustats/netdist.htm. 


\begin{tabular}{|c|c|c|c|}
\hline Ilhas Virgens & 1.5 & Angola & 8.8 \\
\hline Croácia & 5.5 & Maldivas & 12.4 \\
\hline Barbados & 8.6 & Noruega & 1.8 \\
\hline Quênia & 12.1 & Venezuela & 5.9 \\
\hline Austrália & 1.6 & Moçambique & 8.9 \\
\hline Costa Rica & 5.6 & Micronésia & 12.4 \\
\hline Suíça & 1.8 & Iugoslávia & 6.5 \\
\hline Antártica & 6.1 & Haiti & 9.6 \\
\hline KirguiZStão & 9.0 & Madagáscar & 13.5 \\
\hline Iêinen & 12.4 & Bahamas & 2.9 \\
\hline Dinamarca & 1.9 & EI Salvador & 6.6 \\
\hline Aruba & 6.1 & Ilha S. Vincent & 9.8 \\
\hline Panama & 9.0 & Mali & 13.5 \\
\hline Zanzibar & 12.4 & Israel & 2.9 \\
\hline Porto Rico & 1.9 & Líbia & 6.8 \\
\hline Gibraltar & 6.1 & Gâmbia & 9.9 \\
\hline Turkmenistão & 9.0 & Serra Leoa & 13.5 \\
\hline Niger & 12.6 & Mônaco & 2.9 \\
\hline Áustria & 2.0 & San Marino & 6.8 \\
\hline Turquia & 6.1 & Jamaica & 9.9 \\
\hline Gana & 9.1 & Vanuatu & 13.5 \\
\hline Palau & 12.6 & Japão & 3.0 \\
\hline Guam & 2.0 & África do Sul & 6.8 \\
\hline Ucrânia & 6.1 & Tanzânia & 9.9 \\
\hline Ilhas Malvinas & 9.4 & Fiji & 13.8 \\
\hline Paquistão & 12.8 & Coréia do Sul & 3.0 \\
\hline Nova Zelândia & 2.0 & Argélia & 6.9 \\
\hline Rússia & 6.4 & Samoa Ocidental & 9.9 \\
\hline Guiné & 9.4 & Togo & 13.8 \\
\hline Laos & 13.1 & México & 3.0 \\
\hline Finlândia & 2.1 & Tunísia & 6.9 \\
\hline Belarus & 6.5 & Bolívia & 10.1 \\
\hline Ihas Reunião & 9.4 & Cambodja & 13.9 \\
\hline Nigéria & 13.1 & Espanha & 3.0 \\
\hline Irlanda & 2.3 & Colômbia & 7.0 \\
\hline Martinica & 6.5 & Burundi & 10.1 \\
\hline Uruguai & 9.4 & Irã & 13.9 \\
\hline Ruanda & 13.1 & Chile & 3.1 \\
\hline Hong Kong & 2.4 & Marrocos & 7.0 \\
\hline Groenlândia & 6.5 & Belize & 10.3 \\
\hline
\end{tabular}




\begin{tabular}{|c|c|c|c|}
\hline Armênia & 9.5 & Somália & 14.0 \\
\hline Ilhas Ascensão & 13.3 & Vaticano & 3.3 \\
\hline Itália & 2.4 & Papua Nova Guiné & 7.0 \\
\hline Macedônia & 6.5 & Polinésia Francesa & 10.3 \\
\hline Granada & 9.5 & Sri Lanka & 14.0 \\
\hline Omã & 13.4 & Eslovênia & 3.4 \\
\hline Liechtenstein & 2.4 & Azerbaidjão & 7.1 \\
\hline Ilhas Marshall & 6.5 & Kazakhstão & 10.3 \\
\hline Benin & 9.6 & Nauru & 14.4 \\
\hline Congo & 13.5 & Bermudas & 3.5 \\
\hline Luxemburgo & 2.5 & Argentina & 7.3 \\
\hline Romênia & 6.5 & Arábia Saudita & 10.3 \\
\hline Cabo Verde & 9.6 & Nepal & 14.4 \\
\hline Djibuti & 13.5 & Singapura & 3.5 \\
\hline C. do México & 2.6 & Guiana Francesa & 7.4 \\
\hline Suriname & 14.5 & Uzbekistão & 10.3 \\
\hline Malásia & 3.6 & Tajikistão & 7.8 \\
\hline St. Kitts & 7.4 & Sta.Helena & 10.6 \\
\hline Egito & 10.4 & Afeganistão & 16.4 \\
\hline Tuvalu & 14.6 & Grécia & 4.8 \\
\hline Hungria & 3.8 & Samoa americana & 7.9 \\
\hline Tailândia & 7.5 & Zaire & 10.6 \\
\hline Indonésia & 10.5 & Costa do Marfim & 16.4 \\
\hline Ilhas Seichelles & 15.0 & Guatemala & 4.8 \\
\hline Rep Dominicana & 3.9 & Antígua & 7.9 \\
\hline Turks \& Caicos & 7.5 & Guiana & 10.6 \\
\hline Mauritânia & 10.5 & Senegal & 16.5 \\
\hline Mongólia & 15.1 & Eslováquia & 4.8 \\
\hline Taiwan & 3.9 & Botsuana & 7.9 \\
\hline Zimbábue & 7.5 & Diego Garcia & 11.1 \\
\hline Ilhas Mayotte & 10.5 & Etiópia & 16.9 \\
\hline R. da África Central. & 15.5 & Suazilândia & 4.9 \\
\hline Islândia & 4.1 & Lesoto & 7.9 \\
\hline Guadalupe & 7.6 & NovaCaledônia & 11.1 \\
\hline Paraguai & 10.5 & Chade & 18.1 \\
\hline Iraque & 15.6 & Chipre & 5.1 \\
\hline Malta & 4.1 & Honduras & 8.0 \\
\hline Anguilla & 7.8 & $\begin{array}{l}\text { Ilhas } \\
\text { Salomão }\end{array}$ & 11.1 \\
\hline Síria & 10.5 & Myanmar & 19.4 \\
\hline
\end{tabular}




$\begin{array}{lrlr}\text { Tonga } & 15.6 & \text { Ilhas Faeroe } & 5.1 \\ \text { Portugal } & 4.3 & \text { Nicarágua } & \mathbf{8 . 0} \\ \text { Malawa } & 7.8 & \text { Camarões } & 11.3 \\ \text { Barhein } & 10.6 & \text { Ilhas Niue } & 18.4 \\ \text { Vietnã } & 15.6 & \text { Antilhas Hol. } & 5.1 \\ \text { Rep. Tcheca } & 4.4 & \text { Brunei } & 8.1 \\ \text { Ilhas Nevis } & 7.8 & \text { Jordânia } & 11.3 \\ \text { Butão } & 10.6 & \text { São Tomé } & 18.8 \\ \text { Bangladesh } & 16.1 & \text { Bósnia } & 5.4 \\ \text { Polônia } & 4.5 & \text { Macau } & 8.1 \\ \text { Peru } & 7.8 & \text { Ĺbano } & 11.3 \\ \text { Geórgia } & 10.6 & \text { Eritréia } & 18.9 \\ \text { Guiné Equatorial } & 16.1 & \text { Bulgária } & 5.4 \\ \text { Andorra } & 4.6 & \text { Moldávia } & 8.1 \\ \text { Sudão } & 7.8 & \text { Cuba } & \mathbf{1 1 . 4} \\ \text { Montserrat } & 10.6 & \text { Ilhas Cook } & 19.6 \\ \text { Guiné-Bissau } & 15.6 & \text { Estônia } & 4.8\end{array}$

Fonte: ETO

Observação .Os países latino-americanos estão em negrito para facilitar sua visualização comparativa

O cuidadoso trabalho do ETO sugere várias reflexões (vide tabela na página seguinte):

1. A primeira delas é, evidentemente, a dimensão da influência do mercado das telecomunicações no desenvolvimento de cidades como meios inovadores, e portanto, a sua relevância como um dos indicadores fundamentais de meio inovador.

2. A segunda é que a distância ao centro de comunicações não depende tanto do grau de desenvolvimento econômico do país, nem de seu grau de centralidade na conhecida hierarquia da sociedade industrial, mas do modo em que regulam e normatizam os mercados de telecomunicações. Uma prova disto é que países considerados economicamente mais desenvolvidos, como Grécia ou Portugal, são mais periféricos no que se refere aos custos das telecomunicações que outros países menos desenvolvidos, como o México ou a República Dominicana. Embora seja inegável que os países mais desenvolvidos (Estados Unidos, Grã Bretanha, Suécia, Canadá, Austrália, Holanda, Bélgica, França, Alemanha, Noruega, Suíça, Dinamarca - embora as Ilhas Virgens também estejam neste grupo de nova centralidade) possuem distâncias mais curtas.

3. Evidentemente, as distâncias, centralidades e periferias, também dependem do domínio e da propriedade que os países têm das empresas de telecomunicações, e dos acordos realizados entre estas empresas e os respectivos governos, assim como das políticas nacionais de regulação das telecomunicações e das concorrências entre as empresas. E muito provável que, se a empresa de telecomunicações pertence ao mesmo país (por exemplo, Telefônica na Espanha, ou Telecom na França), chegue-se a acordos de preços mais favoráveis para os usuários do que quando estas empresas são estrangeiras no país 
de atuação: como, por exemplo, a Telefônica no Brasil e na Argentina.

4. A quarta é que, embora no caso da nova geografia das telecomunicações criada pelo ElO, se parta de uma unidade de medida simples (lembremos que trata-se do custo relativo dos telefonemas internacionais: o custo das chamadas dos usuários entre o Reino Unido e os Estados Unidos representa uma unidade de distância), no caso do estabelecimento de uma nova geografia de cidades como meios inovadores, as unidades serão estabelecidas com base no cruzamento de indicadores muito mais numerosos e complexos, entre os quais: as políticas locais de telecomunicações, a existência de meios de produção inovadores como pólos tecnológicos, a produção de hardware e software, a existência de universidades que interajam com empresas, o grau de acesso da população às TIC, às inovações sociais, ao consumo de bens e serviços e bens com alto valor agregado em TICs, etc.

\section{Novos indicadores de centralidades e periferias?}

Estes cruzamentos de indicadores deveriam, como expressamos ac rar os seguintes fatores:

a) A concentração regional ou local de atividades de Ciência e Tecnologia qu resulte na produção local de bens e serviços de alto valor agregado em tecnologia da sociedade informacional, incluindo a telemática, mas também biotecnologias que de certa forma também são tecnologias de informação. Isto é, a presença d um sistema de ciência e tecnologia orientado para um desenvolvimento local sustentável, associado a um projeto de país. Isto inclui a existência de pólos tecnológicos, tecnopólis, parques ou cidades da ciência e, em resumo, todas as instalaçõe que promovam a sinergia entre indústrias de alta tecnologia, Universidades e institutos de estudos avançados.

Possíveis indicadores neste campo são os esforços e investimentos locais em C\& T, incluindo tanto governantes como empresários; os programas de apoio ao desenvolvimento tecnológico de pequenas e médias empresas, a existência de incubadoras de empresas, as instalações fiscais aplicadas as iniciativas em $\mathrm{C} \& \mathrm{~T}$, o recursos humanos voltados para a pesquisa básica e aplicada, as áreas de ocupação de profissionais de nível superior, a distribuição de equipes de investigação segundo as áreas de conhecimento.

Isto não só se refere apenas às chamadas ciências duras, mas também às ciências sociais que têm um papel importante a desempenhar na Sociedade do Conhecimento. o avanço do conhecimento científico, assim como o desenvolvimento de questões ligadas às aplicações deste conhecimento, e sua contribuição para a formulação, planejamento, divulgação, etc. de políticas sociais dirigidas para a solução dos problemas sociais, incluindo os relacionados a C \& T.

b) A educação orientada para a produção de novos saberes. Neste caso, podem se considerar indicadores tais como número e qualificação acadêmica de universidades e centros de estudos avançados, gastos públicos e privados em educação ao nível de graduação e pós-graduação, produção científica avaliada pelo número de teses de pós-graduação, incluindo doutorados, publicação de artigos científicos e técnicos, apresentação de trabalhos em eventos de $\mathrm{C} \& \mathrm{~T}$, número de estudantes matriculados e número de estudantes graduados.

Outro indicador importante a se considerar é não só a educação universitária, mas também a primária e secundária. Neste sentido, citaremos novamente Castells (2000), quando expressa que a educação - a partir de um desenvolvimento do sistema educativo - seja capaz de produzir pessoas com autonomia de pensamento e com capacidade de auto-programação e de aquisição de conhecimentos durante o resto de sua vida. Mas é necessário ir mas além, como diz o sociólogo espanhol, em direção ao conceito de cidade educacional: nesta, não se conta apenas com a escola 
como elemento educacional, mas com o conjunto de uma sociedade local, que, através de uma série de interações, incluindo atividades culturais, relações com os meios de comunicação, elementos de animação cidadã, do conjunto do sistema de relações sociais locais, produz um sistema de informação interativa, que desenvolve a capacidade educacional em um sentido mais amplo e não simplesmente de aquisição de conhecimentos. Indicadores válidos seriam não só o número de escolas conectadas à Internet, não só o número e qualidade de cursos atribuí-dos aos docentes, mas também a existência de equipamentos urbanos como museus da ciência, planos de educação, etc.

c) O consumo individual e, sobretudo, coletivo, de bens e serviços intensivos em TIC, isto é, o consumo de serviços urbanos que usam TIC para seu melhor funcionamento e administração: educação, saúde pública, transportes, segurança, integração comunitária, preservação ambiental, etc.; redes técnicas urbanas, como telefonia, eletricidade, gás, água e saneamento, administrada por meio de TIC. Neste caso, os indicadores válidos seriam os sistemas de TIC utilizados, os resultados como eficiência, custos e continuidade dos serviços, sistemas de faturamento, etc.

d) A implementação de diferentes tipos de governo eletrônico nestas cidades. Isto não se limita a abrir portais ou homepages com os dados governamentais para informar os cidadãos e facilitar os trâmites internos; significa, neste caso, colocar o governo local em rede na Internet, de modo a contribuir para produzir uma transformação na cultura política e institucional, para que os cidadãos disponham de acesso às informações que lhes interessam, e participar ativamente nas decisões vinculadas à sua qualidade de vida e a seus direitos como cidadãos. Neste sentido, alguns elementos mensuráveis são os programas de descentralização municipal sustentados por redes informáticas, as redes informáticas de informações intra-institucionais e instituiçãocidadãos, as redes intermunicipais, o acesso a serviços e trâmites via Internet, fóruns de discussão com os cidadãos, programas e projetos de uso de TIC nos governos locais, número e tipo de serviços municipais disponíveis por meios eletrônicos; homepages municipais: conteúdos, serviços para os cidadãos, espaços de interação com os cidadãos, serviços on-line para a comunidade; porcentagem do orçamento municipal destinado a equipamentos de informática e telecomunicações para a Municipalidade e para a formação dos funcionários municipais; porcentagem do orçamento municipal destinado a equipamentos de informática $\mathrm{e}$ telecomunicações para a comunidade e para a formação da população, entre outros.

e) A emergência de novas formas sociais que utilizem como suporte as tecnologias de informação e comunicação. Referimo-nos especificamente às redes eletrônicas cidadãs, sistemas de intervenção, instrumentalização, articulação e promoção do desenvolvimento local. Possíveis indicadores são o número de redes eletrônicas cidadãs existentes, seus alcances, o número de cidadãos que pertencem a elas, suas ações e objetivos, os conteúdos que colocam na Internet, suas homepages, fóruns, listas de discussão, articulação ou associação com redes nacionais e internacionais, sua intervenção, desenho ou difusão de tecnologias adaptadas às organizações do Terceiro Setor.

f) A acessibilidade da população às ferramentas da Sociedade da Informação é, neste caso, um indicador indispensável. A acessibilidade é econômica (mensurável para os custos das telecomunicações, os preços dos servidores da Internet, as políticas e estratégias nacionais e locais para telecomunicações), ou físicas (o número de centros de acesso públicos de Internet, como os telecentros governamentais ou comunitários, privados como os cibercafés, ou os postos telefônicos, ou qualquer uma das variedades emergentes, parque de computadores, número de cidadãos conectados à Internet de suas casas e / ou trabalho, densidade relativa dos navegantes da 
rede. Mas também deve se considerar o acesso cultural às TIC: campanhas de alfabetização tecnológica, criação de conteúdos cidadãos na Rede, rádios comunitárias e jornais eletrônicos na Internet, etc. Outros indicadores necessários do grau de conectividade da população são os endereços dos provedores de Internet (IP), a densidade geográfica dos endereços IP, o número de provedores de Internet, etc.

Estes são só alguns dos indicadores possíveis do grau de inovação em diferentes cidades. Em uma fase posterior, deveriam ser relacionados, não só uns com os outros, mas também com o nível de qualidade de vida nas cidades, para saber se o grau de inovação sócio-técnico influi na melhoria da vida e na cotidiano dos habitantes urbanos. Enfim, este artigo também é o primeiro esboço destes conceitos. Esperamos que a evolução de nosso trabalho nesta direção possa produzir não só uma metodologia adequada, mas também, em um prazo relativamente curto, um novo mapa das cidades centrais e periféricas na Sociedade da Informação.

Resumo - Quais são as implicações dos conceitos de cidades centrais e periféricas, na atual transição para a Sociedade da Informação? Qual o significado da centralidade em um mundo globalizado e numa sociedade de redes? As cidades centrais e periféricas, coincidem necessariamente com as metrópoles dos países centrais e periféricos? Este trabalho se propõe a construir uma base de análise de novos conceitos referentes às hierarquias urbanas específicas da sociedade da informação, assim como esboçar uma primeira tentativa de metodologia de pesquisa voltada para a análise das novas centralidades e periferias urbanas. Não se desenhará o novo mapa urbano da sociedade informacional, mas se oferecerá aos "cartógrafos" sociais algumas ferramentas conceituais para explorar o novo território e explicitar sua geografia.

Palavras-chave - cidades centrais e periféricas, tecnologias de informação e comunicação.

\footnotetext{
Abstract - Which are the current implications of central and peripherical cities conceptualizations, in the current transition to the Information Society? What does centrality mean in a globalized world and in a network society? Do central and peripherical cities, necessarily coincide with central and peripherical countries metropolizes? This essay intends to build an analysis base of new concepts regarding urban hierarchies specific of the information network society, as well as it will sketch a first research methodology attempt aiming to analyze new urban centrality and peripheries. A new urban map of the information society will not be drawn, but it will be offered to social "cartographers" some conceptual tools to explore this new territory and to explicit its geography.
}

Keywords - central and peripherical cities, information and communication technologies.

\section{Bibliografia}

ASIMOV, I. (1978): Foundation. New York: Bantam Books.

BALLARD, J.G.(1962): Billenium. New York: Berkeley Books.

CAMPANELLA, T. J., (1997) "Who says the Net makes cities obsolete?" Salon, August 1997.

CASTELLS, M. (1996): The rise of the network society. Malden, Massachussetts / Oxford, UK: Blackwell, (reprinted 1997).

(2000): La ciudad: políticas proyectos y gestión. Conferência proferida no Salão do Ciento del Ayuntamiento de Barcelona, em 21 de fevereiro de 2000, no ato de encerramento do Mestrado organizado pela Universidad de Barcelona e dirigido por Jordi Borja. (http//:www.fbg.ub.es)

CASTELLS, M. e HALL,.P. (1994) Technopoles of the world. London: Routledge.

CASTELLS, M. e BORJA, J. (1996): As cidades como atores políticos. Novos Estudos Cebrap. $\mathrm{N}^{\circ}$. 45, julho de 1996 [152-166].

CISLER, S. 1995, in Artur Serra "The civic nets What they are, how do they work?" in http://www.ac.upc.es / .

DAVIS, M. (1992) City of Quartz. New York: Vintage Books.

ETO (European Telework Online) (2000) http: www.Telework/netdist.htm 26 de janeiro de 2000

FINQUELIEVICH, S. (1996): Ciberciudades? Informática y gestión urbana. Buenos Aires: Ciclo 
Básico de la Universidad de Buenos Aires (2000) (coord): Ciudadanos, a la Red. Buenos Aires: La Crujía.

FINQUELIEVICH, S. e JARA, A (2000): Community Informatics in Argentina. Act II, Shaping the network society, The Future of the Public Sphere in Cyberspace, A Computer Professionals for Social Responsibility Symposium, http://www.scn.org/cpsr/diac-00, May 20 - 23, 2000. University of Washington HUB, Seattle, Washington, USA

FINQUELIEVICH, S. e SCHIAVO, E. (1998) (coord.): La ciudad y sus TICs. Tecnologias de información y comunicación, Universidad Nacional de Quilmes, Argentina.

FRESSOLI, M. (2001): Apuntes para clase como docente invitado del Seminario Introducción a la Sociedad Informacional, Carrera de Sociologia, Facultad de Ciencias Sociales, Universidad de Buenos Aires. Docentes: S. Finquelievich y S. Lago Martinez.

GIBSON, William (1996): Virtual Light. New York: Bantam Books (1995): Neuromancer. New York: Ace Books.

GURSTEIN, M. (1999) (Ed.): Community Informatics: Using Technology to Enable Community Processes, Hershey PA: Devises Group Publishing.

GURSTEIN, M., \& DIENES, B. (1998): Community enterprise networks: Partnerships for local economic development. Libraries ace Leaders in Community Economic Development conference. Victoria, BC. [online]. Url: http://ccen.uccb.ns.ca/flexnet/ CENs.html

JARA, A. (2000): Las redes comunitarias en el ciberespacio. El caso de la Argentina. In FINQUELIEVICH, S. (coord.): ;Ciudadanos, a la Red!. Buenos Aires: La Crujía.

RANDOLPH, R. (1997) Sociedade-rede: paraíso ou pesadelo? Reflexões acerca de novas formas de articulação social e territorial das sociedades. VI Semana de Planejamento Urbano e Regional. Rio de Janeiro: IPPUR/UFRJ, dez. (2000): Las mutaciones de lo urbano: de la red de ciudades a la ciudad-red. In FINQUELIEVICH, . (coord.): ;Ciudadanos, a la Red!. Buenos Aires: La Crujía. SANTOS, M. (1996): A natureza do espaço. São Paulo: Hutcitec

SASSEN, S. (1991): The global city: New York, London, Tokyo. Princeton, NJ. Princeton University Press (1994): Cities in a world economy. Thousand Oaks, CA.: Pine Forge Press (1996): Globalization and Its Impact on Cities. Public Culture 8.2, Winter. (1996): Whose City Is It? Globalization and the Formation of New Claims. in Holston, J. (ed.) Cities and Citizenship. Durnharn: Duke UniversityPress - Public Culture Book.

SILVA, C. G. da e MELO, L.P. (2001) (coord.): Ciência, tecnologia e inovação - Livro Verde. Brasília: Ministério da Ciência e Tecnologia - Academia Brasileira de Ciências.

VIEIRA, L. (2001): Os argonautas da cidadania. A sociedade civil na globalização. Rio de Janeiro: Record. 